\title{
Nutritional management after colonic interposition
}

Basson A, MS, RD Lecturer and Hospital Student Internship Supervisor, University of the Western Cape Correspondence to: Abigail Basson, e-mail: abbasson@uwc.ac.za Keywords: colonic interposition, nutritional management

\section{Background information}

The patient, a 22-year old male, was admitted on 5 0ctober 2009 after a suicide attempt by ingestion of caustic fluid (JIK ${ }^{\circledR}$ bleach). The patient was human immunodeficiency virus (HIV) positive, stage 2 , with a CD4 count of 275 , and no other relevant medical history. On admission, he was underweight with a body mass index (BMI) of $14.8 \mathrm{~kg} / \mathrm{m}^{2}$.

\section{Case history}

An emergency total gastrectomy, splenectomy and oesophagectomy with blind loop oesophagus was performed on 6 0ctober 2009 and a feeding jejunostomy (PEJ; tube size 14) was inserted. Two litres of a standard polymeric fibre-containing ready-to-hang feed was started via the PEJ at $83 \mathrm{ml} /$ hour (run over 24 hours) for inpatient nutritional rehabilitation and maintenance. Three months later the patient was discharged and managed at home on 2 litres standard polymeric (reconstituted powder) bolus feeds of $250 \mathrm{ml}$ per bolus. The patient was referred for a colonic interposition and readmitted in May 2010. At that time, feeds were recalculated and changed to 1 litre high-protein and 1 litre fibre-containing polymeric feed to continue nutritional rehabilitation based on the patient's weight of $56 \mathrm{~kg}$ and $\mathrm{BMl}$ of $18.7 \mathrm{~kg} / \mathrm{m}^{2}$. The colonic interposition surgery was performed on 13 July 2010. The surgery was complicated by restenosis of the proximal anastomosis causing continued reflux and aspiration and one course of aspiration pneumonia, that was treated. An oesophagoscopy further revealed severe laryngeal fibrosis and vocal cord paralysis. On 13 January 2011 a total laryngectomy with tracheostomy placement and revision of the pharyngeal-colonic anastomosis was performed to restore swallowing ability.

\section{Diagnosis}

Colonic interposition with previous total gastrectomy, splenectomy, oesophagectomy and laryngectomy secondary to caustic ingestion.

\section{Anthropometry}

The patient's height was $170 \mathrm{~cm}$. His weight and BMI values are shown in Table I.

Table I: Weight and body mass index

\begin{tabular}{|l|c|c|c|}
\hline & October 2009 & May 2010 & July 2010 \\
\hline Weight (kg) & 43 & 56 & 59 \\
\hline BMI (kg/m²) & 14.8 & 18.7 & 20.4 \\
\hline
\end{tabular}

\section{Nutritional management}

Colonic interposition is the surgical reconstruction of the oesophagus whereby part of the colon is used to replace the oesophagus, particularly in patients who require an oesophagectomy for nonmalignant diseases. ${ }^{1}$ Accidental or intentional ingestion of caustic substances may have devastating effects on the oesophagus, stomach and small bowel, and may lead to corrosive strictures and necessitate partial or total removal of these organs. Corrosive strictures of the oesophagus arise in $85 \%$ of caustic ingestion patients, regardless of the type of immediate treatment. ${ }^{2}$ Consequently, patients usually require multiple dilations, supplemental feeding via jejunostomy and, ultimately, some form of oesophageal reconstruction. Additional indications for the surgery include oesophageal cancer, neuromotor dysfunction (e.g. achalasia), strictures and Barrett's oesophagus with high-grade dysplasia. ${ }^{3}$

If the length of the remaining oesophagus is too short, or a total gastrectomy has been performed, or if there is inadequate vascularisation in the remaining stomach, a colonic interposition may be indicated over a gastric pull-up. ${ }^{4}$ The colon is a durable alternative to the oesophagus, owing to its resistance to gastric juices and its peristaltic ability. Either the left or the right colon may be used to replace the oesophagus. The left colon is usually preferable because of its smaller diameter, lower tendency for dilation, more reliable 
blood supply and adequate length for reconstruction. In this regard, the left colonic segment, using the inferior mesenteric artery, has been shown to be superior to the right segment based on the middle colic artery. ${ }^{1,5}$ Preoperative endoscopic evaluation of the pharynx and remaining cervical oesophagus is utilised to examine the site of anastomosis, while a barium enema and/or colonoscopy is used to evaluate the vascular supply of the proposed segment of colon. Complications are primarily respiratory in nature, either associated with an intrathoracic anastomotic leak or related to the complexity of the operation and systems involved. ${ }^{6-8}$

In oesophageal reconstruction, six to 12 months is the recommended waiting period, from the time of caustic ingestion until surgery to allow complete scarring of the oesophagus. ${ }^{2,9}$ It is essential that adequate nutrition be maintained during this period to ensure optimal postoperative wound healing, and a PEJ is invariably placed preoperatively and maintained postoperatively until the patient is able to consume adequate nutrition orally without complications. A larger bore jejunostomy tube may be advantageous over a needle catheter jejunostomy, to reduce the incidence of obstruction of the tube by formula and medications, and facilitate home management before the surgery. ${ }^{3}$

The European Society for Clinical Nutrition and Metabolism (ESPEN) guidelines for the management of intensive care patients recommends the use a total of $25-30 \mathrm{kcal}(105-126 \mathrm{~kJ}) / \mathrm{kg}$ body weight/day; however it is recommended that $40-50 \mathrm{kcal}(168-$ $210 \mathrm{~kJ}) / \mathrm{kg}$ of current weight and 1.6-1.8 g protein $/ \mathrm{kg}$ current weight be used for HIV patients with wasting. ${ }^{10,11}$ In this case, the HIV-based recommendations were used to calculate the patient's caloric and protein requirements using his current weight, and were adjusted according to weight gain.

The patient was managed long term (in hospital) on cyclic feeds running over 16-18 hours, based on maintaining a glucose oxidation rate of less than $7 \mathrm{~g} / \mathrm{kg} /$ minute to minimise adverse metabolic consequences. $^{12}$ Oral nutrition was initiated for the first time on 26 May 2011, one and a half years after the initial admission date. At this time, a speech therapist assessed the patient's functional swallowing and the patient was managed on liquids, jelly and custard before advancing to pureed food and then a soft diet.

The challenge in feeding patients with a colonic interposition is that they have an anastomotic site both in the oesophageal and colonic regions of the gut, making feeding difficult distal to the site of either anastomosis. However, with regard to a colonic anastomosis, ESPEN guidelines recommend that a standard whole-protein formula (immune-modulating formula may be used in patients with obvious nutritional risk or in those undergoing major cancer surgery) can be started on the first or second postoperative day at a low flow rate of 10-20 ml/hour as evidence has not demonstrated impairment of anastomotic healing. However, achieving target intake may take five to seven days, but this is not considered harmful. ${ }^{13}$
The guidelines on the management of the oesophageal anastomosis are less clear and patency must first be checked before a liquid diet is started, generally around day six to nine. ${ }^{2-4}$ If a leak develops, the patient will remain without oral intake, and feeds must be provided via the jejunostomy. Unless there is intolerance to enteral feeding due to postoperative ileus or chylothorax, parenteral nutrition is not indicated. Once a barium swallow has confirmed that oral sips may be started, aspiration risk and swallowing difficulty must be assessed in these patients by a speech therapist. This specialist will determine tolerance to liquid and/or solid food consistencies, along with any additional recommendations concerning head positioning during swallowing and swallowing exercises to improve eating and drinking abilities.

After a full liquid diet has been established, the jejunostomy feeds are changed from a continuous to a cyclic infusion of 12-14 hours (night feed), allowing oral intake during the day. In the absence of weight loss or other postoperative complications, oral intake usually progresses from clear liquids to full liquids to a soft diet. ${ }^{3}$

General dietary recommendations for postoesophagectomy/oesophageal reconstruction include: ${ }^{14,15}$

- Consume a bland diet consisting of soft, moist foods that are easier to swallow.

- Avoid doughy breads and gummy and stringy foods.

- Avoid gas-forming foods and carbonated beverages.

- Eat small frequent meals (six to eight per day).

- Eat food slowly and well, and stop eating upon feeling full.

- Avoid lying down for 30-60 minutes postprandially.

Patients with an additional total gastrectomy may be at the increased risk of developing dumping syndrome, and therefore should also avoid consuming sugar-rich foods and drinks with liquids in between meals, in addition to the above guidelines. Gastrectomy patients are also at risk for fat malabsorption, and iron-deficiency, pernicious and megaloblastic anaemia. Haematological status should be regularly assessed, and vitamin $B_{12}$ and folate supplementation may be necessary. ${ }^{16}$ Patients should be advised to keep their upper body at a 30-degree upright angle while sleeping, to avoid reflux and possible aspiration arising from the absent gastro-oesophageal sphincter. ${ }^{3}$

A long-term clinical evaluation of colonic interposition patients documented that recovery of full swallowing ability required a median of two months. Additional side-effects unrelated to gastrointestinal function included nocturnal regurgitation, gurgling, early satiety and offensive breath, although these side-effects were not regarded as significant. ${ }^{1} \mathrm{~A}$ later study found that fullness after meals was the primary complaint $(36 \%)$ in colonic interposition patients up to nine months postoperatively, while no complaints of vomiting during and after meals, regurgitation and pillow staining were reported, compared with those who underwent a gastric pull- 
up where vomiting before and after meals $(30 \%)$, regurgitation and pillow staining $(27 \%)$ were reported at 15 months postoperatively. Twenty-five per cent of patients with gastric pull-up had (remnant) reflux oesophagitis at 15 months' follow-up, while no oesophagitis was observed in patients with a colonic interposition at any time. ${ }^{4}$

In keeping with the current literature, jejunostomy feeds in this patient were restarted postoperatively within 48 hours using a standard polymeric feed after the colonic interposition. Because of the postoperative complications, the patient was maintained on PEJ feeds for an additional seven months before laryngectomy and revision of the pharyngeal-colonic anastomosis. Twelve days after the laryngectomy, a barium swallow revealed no leaks, stenosis or aspiration, and the patient was commenced on a liquid diet, experiencing regurgitation only in the supine position. Two days later the patient was started on pureed foods as per the speech therapist recommendation. The patient required encouragement and reassurance to overcome the fear of eating.

Once oral intake had been well established, PEJ feeds were discontinued. However, the PEJ was not removed until several outpatient visits later, in case of complications. The patient was appropriately counselled as per the gastrectomy and oesophagectomy dietary guidelines throughout the course of rehabilitation.

\section{References}

1. De Meester TR, Karl-Erik J, Franze I, et al. Indications, surgical technique, and long-term functional results of colon interposition or bypass. Ann Surg. 1988;208:460-473.

2. KneževićcJD, RadocanovićNS, SimićAP, et al. Colon interposition in the treatment of esophageal caustic strictures: 40 years of experience. Dis Esophagus. 2007;20:530-554.

3. Kight CE. Nutrition considerations in esophagectomy patients. Nutr Clin Pract 2008;23:521-528.

4. Yildrim S, Koksal H, Celayir F, et al. Colonic interposition vs. gastric pull-up after total esophagectomy. J Gastrointestinal Surg. 2004:8:675-678.

5. Wilkins EW Jr. Long-segment colon substitution for the esophagus. Ann Surg. 1980;192:722-725.

6. Kolh $\mathrm{P}$, Honore $\mathrm{P}$, Degauque $\mathrm{C}$. Early stage results after oesophageal resection for malignancy-colon interposition vs gastric pull-up. Eur J Cardiothorac Surg. 2000;18:293-300.

7. Collard JM, Otte JB, Reynaert MS, et al. Esophageal resection and bypass: a 6-year experience with low postoperative mortality. World J Surg. 1991;15:635-641.

8. Dumont P, Wihlm JM, Hentz JG, et al. Respiratory complications after surgical treatment of oesophageal cancer. A study of 309 patients according to the type of resection. Eur J Cardiothorac Surg. 1995:9:539-543.

9. GerzicZZ, Kneževic J, Milieævic M. Esophagocoloplasty in the management of postcorrosive strictures of the esophagus. Ann Surg. 1990;211:329-336.

10. Kreymann KG, Berger MM, Deutz NEP, et al. ESPEN guidelines in enteral nutrition: intensive care. 2006;25:210-223.

11. Fenton M, Silverman EC. Medical nutrition therapy for human immunodeficiency virus (HIV) disease In: Mahan LK, Escott-Stump S, editors. Krause's food, nutrition, and diet therapy. St Louis: Saunders Elsevier, 2008; p. 991-1020

12. ESPEN. Board of directors and the clinical guidelines task force guidelines for the use of parentera and enteral nutrition in adult and paediatric patients. J Parenter Enteral Nutr. 2002;26(suppl):22A-24A.

13. Weimann A, Braga M, Harsanyi L, et al. ESPEN guidelines on enteral nutrition: Surgery including organ transplantation. Clin Nutr. 2006:25:224-244.

14. Ginex PK, Hanson J, Frazzitta BL, Bains MS. 100 questions and answers about esophageal cancer Sudbury, MA: Jones and Bartlett; 2005

15. Wagner K, Claghorn K. Post-esophagectomy diet. Abramson Cancer Center of the University of Pennsylvania [homepage on the Internet]. c2011. Available from: www.oncolink.org/coping/article. $\mathrm{cfm} ? \mathrm{c}=3 \& \mathrm{~s}=64 \& \mathrm{sS}=158 \&$ id $=989 \& \mathrm{p}=2$

16. Thomas B. Disorders of the stomach and duodenum. In: Thomas B, editor. Manual of dietetics practice. Oxford: Blackwell Publishing, 2001; p. 353-357. 